\title{
Leadership, authority and crisis: reflections and future directions
}

\author{
Dermot O’Reilly, Claire M. Leitch, Richard T. Harrison and Eleni Lamprou
}

\section{Introduction}

As we noted in the introduction to this Special Issue, discussion of the relationship between leadership and crisis is not new. For some, the emphasis is on crisis, or the sense-making that takes place in crisis situations (Weick, 1988), on asking what leadership is produced in times of crisis (Mabey and Morrell, 2011), and on asking what leadership is appropriate for times of crisis (Chambers et al., 2010). For others, leadership itself is the focus, revisiting notions of leadership which are problematized by the occurrence of crises (Grint, 2005; Probert and Turnbull James, 2011), reconsidering the relationship between crisis and forms of charisma (Bligh et al., 2005; Williams et al., 2009); or viewing crises as windows of 'dangerous opportunity' (Musselwhite and Jones, 2004) for incumbent or aspiring leaders (Ulmer et al., 2014).

'Crisis' itself is no longer considered to be an occurrence or a one-off event but instead can be viewed as endemic and constitutive. For instance, for Virilio (2012) the twenty-first century world has been transformed by three events or bombs: first, the atomic bomb, which introduced a new degree of militarisation and fear of its consequences; second, the ecological bomb represented in global warming and environmental changes (rising sea levels, ablating polar ice caps, extreme weather events); and third, the informational bomb, the instantaneous means of communication and transmission of information that made possible, for example, both the Arab Spring and the global financial crisis. The legitimacy of leadership, for many commentators, has been challenged by these events, not for what it did but for what it did not do. As with Sherlock Holmes' reference (in Silver Blaze) to the curious incident of the dog in the night-time (what was curious was that 'the dog did nothing in the night-time') leadership is widely represented as the dog that did not bark. This can be explained by four defining characteristics. First, it is introspective exemplified, by Foley's (2013) reference to a new strand of leadership studies which celebrates the benefits of introspective leadership and contrasts it with the more conventional benchmarks of standard-issue extroverts in leadership positions. Second, it is decontextualized: the 'homogenised perspective' of decontextualised leadership has become hegemonic in many advanced economies with a shift towards decentralisation, marketisation and performativity (Mertkan, 2014). Third, it is atomistic as has been highlighted in Contractor et al's (2012) distinction between atomistic, individual-focused and molar team-focused approaches to networks and collective leadership. Finally, it is ineffectual, illustrated by Obolensky (2014) in the parallels he draws between leadership and the Red Queen effect in Lewis Carroll's Alice in Wonderland, who runs very hard just to keep up, but gets nowhere fast.

The collection of papers in this Special Issue address some of these issues in examining leadership and crisis across a diversity of contexts. In this closing essay we review some of the themes that come from reading across these articles and revisit the motivating themes behind the initial call. Each of the papers presents a distinct contribution in its own right. They variously provide detailed interpretations and critical analyses of leadership construals (construals by leaders) and construals of leadership (construals of leaders and leadership) in the context of crisis construction. Reading across them, however, - exploring commonalities and noticing unexpected congruences and contrasts - proffers a range of other insights, conjectures and spaces for reflection and potential directions for future research. Moreover, 
they also offer an opportunity to revisit and extend some of the motivating themes for this Special Issue.

A striking impression from the articles, in the light of our comments above, is the continued romance of leadership and of leaders, especially in times of crises, which raises questions around the cultural power of the symbol of leadership. A further sensibility evoked across the articles is of the many and varied ways in which leaders, leadership and crises are represented, displayed and brought into being. This leads back to a reconsideration of the notions of construal and construction that we initially invoked in the call for papers in order to distinguish between linguistic representation and material causation. We revisit this conceptualisation and utilise the notion of intertextuality as a means of developing a more sophisticated and adequate account for addressing these distinctions.

A number of more specific questions from the call for papers are also called into play, in particular the question around the role of those in power in construing and constructing crises and the question as to whether crises entail new forms or processes of leadership. Also, we revisit Mabey and Morrell's contention that the recurrence of crises suggests that leadership studies are suffering from a type of legitimation crisis.

From each of these considerations a number of potential directions for future research ensue. Two particular avenues, however, generate more prolonged discussion and these will be presented in more detail at the end of this article. First, we consider the potential of multiperspectival and intertextual analyses for developing more fine-grained and satisfactory accounts of the various forms of construal and construction. Second, we argue for the importance of integrating analyses of power and authority, specifically using resources such as political ecology and political economy which foreground analyses of the relations between power and material-institutional-structural trajectories, into critical leadership studies.

\section{Key issues in leadership and crisis research}

The continuing romance of leadership (and its discourses), even (or especially) in crises

The first three articles, in various ways, point to the continuing romance of leadership (Meindl et al., 1985), or perhaps more accurately, the romance of leaders. In Case et al's article the proclivity within environmental science literature to assume that leadership can be located in individual positional leaders is identified - with one study even regarding leadership in binary fashion, that is as present, or not present. In Liu's article accounts were developed of how the banking leaders were attributed or self-attributed themselves with versions of 'practical wisdom' (phronesis). These were often inferred from their purported experience, knowledge, or evocation of other fields (sports, nurturing, the military). In Bresnen et al's article the valorisation of leadership is displayed in the positive descriptions of leadership by the respondents in comparison to those of management. The fourth article by Eslen-Ziya and Erhart, however, examines a case where protestors appeared to reject a leader in favour of leaderlessness, a qualitatively different mode of horizontal rather than hierarchical leadership.

A striking feature about these instances of the romanticisation of leadership in the first three articles is that they occur especially, not even, in instances where crises have been representationally constructed. This chimes with a recent article by Knights and McCabe (2015) in which they argue that discourses of crisis and leadership share the same 
assumptions and representations that the future is knowable and controllable via quasiscientific processes and economically rational strategizing. So, whereas it has been held that crises raise questions about the legitimacy of those in power (e.g. Boin et al., 2009; Madera and Smith, 2009), in fact, whether or not particular incumbents are rhetorically delegitimized in one respect (e.g. banking leaders in the US and UK), their modes of rationality (and the institutional structures that implement these rationalities) are not. The irony of these apparent 'legitimation crises' (cf Habermas, 1975) of those in formal leadership positions, therefore, is that despite their authority being questioned by the occurrence of crisis, it is also buttressed because the instrumental-rational authority of, and surety in, their modes of operation tends to be assumed by those doing the questioning.

The romanticisation of the language of leadership is also remarkable. Two of the articles (those by Case et al and Bresnen et al) clearly show the conceptual, symbolic and cultural importance assumed and assigned to the linguistic terms 'leaders' and 'leadership'. Case et al demonstrate that a number of writers within environmental science assume that leadership is a solution to environmental crisis, rather than recognising that the practice of leadership must also be implicated as part of the problem of any ecological crisis. One of Bresnen et al's respondents mentions the need to be able to inspire 'awe' in others in order to be a 'leader', exemplifying this heroicization and idealization of leadership. The other two articles, however, focus less on the language of leadership per se, but on the broader linguistic features used by and about leaders. Liu's analysis of sports, military and caring metaphors in relation to the depiction of Australian banking leaders are an interesting means by which the media personalizes leadership (that is, reduces the phenomenon of leadership to the formal leader), but also makes the leaders personable i.e. relatable, familiar and understandable. This mode of heroicisation neatly accomplishes both venerating the formal leaders as well as placing them in a shared representational relationship with the audience. Eslen-Ziya and Erhart's article, in contrast, includes interesting subversions of the language of the formal leader, the Turkish Prime Minister, by the protestors. Accordingly, they recast a phrase by the Prime Minister that each family should have 'at least three children' to 'at least three books' (making links to claims for education) and 'at least three beers' (referencing and contesting recent legislation banning alcohol use in public), amongst others. These subversions of a leader's language only work because of the status conferred upon the leader's talk, so even these disparagements of a leader's talk depend on the romanticization or status of the leader's language for their impact.

This symbolic and cultural relevance of the category of leadership seems to tend to override its deficiencies in enabling communication or articulation in particular contexts. This implies that the discourse of leadership holds a relatively superordinate position in comparison to other discourses within the discursive field. We can assume, however, that the positioning of discourses to each other is relational and contingent, and not simply static or uniform. For example, (Gruber, 2010: cited in Case et al) found that leadership is identified as important almost twice as often in research literature than in practitioner literature (in the environmental research domain). This implies that the discourse of leadership may be particularly dominant in academic literature. If this is the case even in environmental research, then to what extent is this research bias for identifying the importance of leadership evident in other research contexts?

The constructions of leadership uncovered by the articles are therefore primarily heroic, involving command, interpersonal persuasion, perseverance and know-how. Grint's work (Grint, 2005; Grint, 2010) suggests that critical problems or situations (at least, those that are 
successfully constructed as such) suffer from what he calls the irony of leadership. That is, whereas such situations would be opportune for leadership processes that are open, exploratory, mutual and questioning rather than directive, ends-focussed, asymmetrical and based on the assumption of knowledge, instead they are more likely to favour the imposition of uni-directional leadership processes. This is because the spectre of crisis defaults people's responses into this mode of operation, which is assumed to be effective. Indeed, there is an evident lack of democratic, participatory and exploratory leadership practices reported in the articles - other than some limited evidence of democratic governance mechanisms referred to in Case et al, and Eslen-Ziya and Erhart's discussion of horizontal and postheroic leadership amongst the Gezi protestors. This would tend to support Grint's observation that successfully constructed crises are associated with uni-directional leadership practices.

These two aspects of the mutual relationship between constructions of leadership and crisis (that is the continued cultural and symbolic strength and resonance of the romance of leaders, leadership, and their discourses as well as the propensity for crises situations to be associated with uni-directional leadership practices) both raise questions about the potential project of critical leadership studies, which we develop below in the discussion of future research.

\section{Intertextuality, construal and construction}

There is significant intertextuality evident in each of the papers in that texts around leaders and leadership refer to and incorporate elements of others texts and appear in other contexts. Case et al. did not look specifically for intertextuality, but their findings on the assumed importance of leaders, through their personal characteristics and their formal positions, indicates that they found it. However, thus might be better termed as interconceptuality, the re-occurrence of significantly similar concepts and assumptions in different texts, rather than as intertextuality per se. Liu expressly utilised the concept of intertextuality to look at the similarities and differences between different texts in the Australian media, in comparison to bankers' retrospective accounts. The media texts clearly contained explicit references to other texts, as well as significant similarity in their concepts and assumptions, whereas the bankers' retrospective accounts contained significantly divergent concepts and assumptions, both about the context and of their role. Bresnen et al.'s findings on the comparisons made between leadership and management by their respondents echoed significantly with some of the standard depictions and descriptions of leadership and management in the mainstream literature. This indicates that these conceptual frameworks and distinctions were culturally embedded for significant numbers of NHS middle-managers, and that some of these leadership concepts had significantly colonised this context. In contrast, the slogans used by the protestors reported upon in Eslen-Ziya and Erhart's article drew heavily from intertextual tactics of appropriation and recontextualisation in that excerpts of texts used by the authorities were taken, modified and placed in a different context. Some of the protestors' discursive tactics, e.g. 'get your hands off my body', explicitly targeted the colonising language of the authorities, thus seeking to disrupt the discursive constructions of the Turkish state.

The importance of intertextuality in discursive and semiotic construction, and how it relates to material construction, is thus something that is raised across the articles. In the call for papers we had invoked a distinction from Sayer (2000) between construal and construction, which attempts to articulate a difference between discursive or semiotic representations, and representations that become enacted (representations that are used), inculcated (representations that are not merely used, but become a way of acting in the world) and materialised (representations that result in their being incorporated within material processes) 
(FaIrclough, 2010: pp.210-11 and pp.500-501). Sayer's distinction between construal and construction is intended as a means for both indicating the potential causal relation between the realm of the semiotic and the realm of the material, and for enabling the empirical evaluation of how some construals become selected into and retained in material processes, whereas others do not.

The types of intertextuality present in the articles in this Special Issue, however, imply that there is not only a potentially complex process between semiotic (or discursive) construal and material construction, but also that multiple construals are variously (to different degrees), and simultaneously, constructed into different social-material processes. For example, in Bresnen et al's article the distinctions between leadership and management appear to have been materially reproduced in the teaching content of the leadership development programmes to which many of the participants had been exposed. Yet, even though these discourses were then enacted, at least to some degree, by the respondents, they also had difficulty in applying them to descriptions of their own and others' practices. Even though the semiotic representation of leadership was constructed into social-material processes of interpreting and describing idealised ways of being and practice, this was, at most, only partially constructed into actual ways of being and practice (albeit that the discourse of leadership remained symbolically and culturally significant for the respondent's meaningmaking). At the same time other discourses and practices of management clearly had a conspicuous material impact and effect on their everyday experiences.

The articles suggest, therefore, that we not only require a distinction between construal and construction, but that we also need to look at the multiple forms of intertextuality, and also the interpenetrations between different types, levels and arenas of texts, language-in-use, identities, social institutions and social-material practices. In the remainder of this article we retain Sayer's distinction for simplicity's sake and return to these complexifying issues in the discussion of future research.

The role of those in power in the construal and construction of crises

The role of those in power in the construal and construction of crises appears variably in the articles. Case et al.'s article raises fundamental questions about who is in power and to what extent they are able to construe and construct crises. Those in forms of political and corporate power are present in the articles reviewed as the holders of formal leadership positions. Political positions are particularly present as they are often involved in the setting-up, negotiation and evolution of the environmental governance mechanisms being examined. Those in administrative positions in these governance mechanisms are also examined, while corporate positions appear to be implicitly included in some of the mechanisms studied, and in some of the studies those in local or traditional leadership positions are included. The articles reviewed by Case et al (2015) generally do not appear to tell (or indeed, appear to try to tell) how these political, administrative, corporate and local positions in environmental governance mechanisms articulate with broader political, administrative, corporate and social formations and structures. That is to say, the presence of these environmental governance mechanisms indicates that the power to construe and construct environmental issues and crises is clearly present to some degree, but who precisely has been involved in this, and in what ways, warrants further examination.

The actors involved in construing and (perhaps) constructing environmental crises that is particularly highlighted by Case et al are environmental science writers and researchers. Their role as scientific authorities in an instrumentally-rational context is raised and 
problematized by Case et al's analyses. Considering their apparent construal and semiotic construction of environmental crisis, however, it is starkly revealing that the governance mechanisms examined appear to be of a scale ill-suited to a potentially global issue. Scientific authority, therefore, appears to be currently subservient to other forms of power and authority in this field.

Liu's account suggests that once a construal of crisis has been accepted and performed in one location, that it is relatively easily spread to another. Further, it may not even be formal leaders that promote the construal and construction of a crisis or its spread. Rather media construals appeared to be significant in this context, and they also appeared to be favourable to leaders' self-representations of appropriate action since their banks did not experience significant trauma. Indeed the similarity of the media construals of crisis in the Australian context to US and UK contexts implies that the newsworthiness of crisis construals makes them as socially contagious as attributions of leadership (a la Meindl).

Bresnen et al's article indicates that those in subordinate positions in the politicaladministrative complex of public services are primarily required to accept and work with the construals and constructions of their political-administrative superiors. In this instance, semiotic and discursive construals of crisis did not appear to be the primary constructing force, rather the institutional and bureaucratic imperatives from their superiors appeared to be the driver of the respondents' day-to-day experiences. In some ways, Eslen-Ziya and Erhart's article also displayed the importance of material power in constructing crisis. The respondents' views of the Turkish Prime Minister not only indicated their displeasure with his construals of women's role in society, but also with the resulting legal, administrative and social measures that impacted on their day-to-day lives. The Prime Minister was not construing a crisis, but the state's resultant actions created a situation that the respondents construed as a form of crisis, that is an attack on their personhood.

These articles, thus, point to the various types of power and authority present and mobilised in construals and constructions of crises, and how these inter-relate with concomitant construals and constructions of leadership. In each case the perspective of political ecology (Case et al's article in particular) or political economy (the other articles) is subtly present. Such perspectives are crucial for understanding the grounding and trajectory of different social, political or professional groups or factions, and the forms of power available to them. This focus on power and authority and its relationship to questions of construal and construction relates strongly to the question of the potential project of critical leadership studies that we develop below in the questions for future research.

Do crises entail new forms or processes of leadership?

It has been argued by some writers that crises can afford a window of opportunity to leaders to demonstrate their effectiveness (Boin et al., 2009; Madera and Smith, 2009). Successful representations that use crisis language are held to disrupt business as usual enabling potential claims-makers to exploit crises as an opportunity to innovate new forms of explanation and diagnosis. Exploiting a crisis then requires leaders, whether aspiring or incumbent, to focus the blame of the crisis on others and position themselves as agents of change (Boin et al., 2009). Elsewhere, however, Boin and t'Hart (2003) question this argument and instead contend that in actual crises the demands of crisis management are at odds with strategies of change or reform which can result in quite limited opportunities for change. The article by Liu, and the situation described in Bresnen et al. also suggest that the 
changes actually experienced post-crisis are incremental and broadly consistent with the previous trajectory, even reinforcing and strengthening them (even if particular incumbents are displaced) rather than revolutionary. Only the article by Eslen-Ziya and Erhart indicates that crises do create a potential for change. However, it is important to note that although the Gezi protests did result in concessions from the Turkish government and arguably have helped create an alternative consciousness (Letsch, 2014; Letsch, 2015; Perry, 2015) they have not, yet at least, fundamentally altered the power formations and structures in Turkey.

The answer to the question 'do crises entail new forms or processes of leadership?', is thus mixed as crises may entail new forms or processes of leadership, or they may not. It appears to be affected by who the actor(s) construing the crisis, their behaviours, their forms and modes of power and authority (again raising the questions of political ecology and political economy), the material and social-institutional counterparts to the semiotic construals as well as the concomitant actions and responses of other actors.

\section{The legitimation crisis of leadership studies}

Given that the recurrence of crises suggests the limited success of leadership studies in addressing well-worn vices in the practice of leadership such as corruption, narcissism and conflict, Mabey and Morrell (2011) have raised questions about the legitimation crisis of leadership studies. Vices in the practice of leadership, however, do not necessarily equate to flaws in all of the study of leadership. Perhaps Mabey and Morrell's implicit expectation for knowledge to remove or obstruct human vices is too high an evaluative threshold for any academic discipline, and the most we can expect is the potential minimisation of human vices. While Mabey and Morrell appear to hope for academic research to afford both understanding and effective input into (if not control of) social phenomena, academic research tends to be propositional and/or problematising in nature both of which lead to knowledge which is insufficient for most practical action. Academic research is currently (and as far as can be currently foreseen) restricted to discursive knowledge - that which can be put into words. Such knowledge is of a different nature to other forms of semiotic knowledge (the meaning of an embrace, for example) and forms of non-semiotic knowledge (the knowledge from the personal experience of being cut by a serrated edge, however perspectival and situated that knowledge, is of a fundamentally different type to any communicative expression, description or explanation of it). We need to recognise the limitations of academic research, and not bemoan them overmuch or wish them away.

Mabey and Morrell thus appear to hope for an enlightened functional, instrumental or perhaps pedagogical role for leadership studies. While we understand the sentiment behind the desire that academic research might have some tangible material effect on the world we believe that even this sentiment must be exposed to critique and questioning. The standard critical questions on functionalist and instrumentalist perspectives cannot be neglected: for whom is this functional or instrumental? What purposes or interests are being served, and whose interpretation is used?

Our argument, therefore, would be that the field of leadership studies is in no more or no less of a legitimation crisis than any form of academic research where post-positivist methodologies and functionalist assumptions account for the majority of the research. While the occurrence of social crises would seem to delegitimate these forms of research, the irony of legitimation crises, as suggested above, is that even though the grounds for reasoned legitimacy appear discredited, the material and social structures and processes that exist before the crisis tend to continue afterwards. In such a context critical leadership studies, in 
particular, should not be concerned with directly informing action. Even though there may be roles for critical action researchers and others to complement or catalyse such knowledge, the knowledge of practical action is most suitably developed by practical activists, Rather, critical leadership studies should be concerned with critiquing power, inequality and other asymmetries. While strands of it should offer some broad suggestions and ideas for practical action, these suggestions need to be recognised as partial and insufficient, since it needs to be recognised that they too will have implications for the reproduction of power relations, inequality and asymmetries.

\section{Agenda for future research}

From the foregoing discussions there are a number of both quite specific and broader avenues open for future research on crisis and leadership. A specific question, but with quite broad potential applications and ramifications relates to the issue of the potential for crises to act as catalysts of change. As indicated above, the examples in the articles discussed suggest that the changes actually experienced post-crisis are often incremental and broadly consistent with the previous trajectory (even if particular incumbents are displaced) rather than revolutionary. Future research could examine when and why this is the case, and what combines to make crises augment the power of those in power (or the structures and processes that enable or reproduce them), or undermine them (or the structures and processes that stall or unseat them)?

Another issue discussed above that generates a broad number of potential lines of inquiry is the relationship between construals and constructions, which is of relevance for consideration of crises in particular, but also more generally. As argued, while useful, this distinction is not sufficient in itself to account for different types and forms of construal and construction and how they might inter-relate. Future research could attempt to account for the relations between (at the least) semiotic construals, constructions, enactments and inculcations, institutional construals, constructions and materialisations, and socio-material construals, constructions and materialisations. The role of historical-cultural trajectories in impacting on discursive, material and institutional construals and constructions is also ripe for further exploration and development.

As argued previously, multi-perspectival and intertextual analyses may be a fruitful avenue for developing this sensitivity between construals, partial-constructions and multipleconstructions. Intertextual analysis also requires intercontextual analysis, namely, there is a need to look at not only the interrelations between different texts and forms of construal and construction, but also the field relations between the agents involved in the negotiation of crisis construals and the various types and levels of constructions consciously and unconsciously produced.

\section{Critically studying leadership - the need for political ecologies and economies}

Case et al provide an example that directly answers one of Mabey and Morrell's questions how to consider followers and the context without losing sight of the individual leader. Their answer is to take a multi-perspectival approach to analysing leadership activities, including not only the leader, but also the processes, positions, purposes and results of leadership. However, their critique of environmental leadership literature shows that the problem is not so much the occlusion of the individual leader in this field, but its continued overemphasis and romanticisation. 
The continued cultural and symbolic resonance of leaders and leadership noted above raises questions about the potential project of critical leadership studies. There are now established bodies of work that question, debunk and undercut the pretensions of leadership (even if the majority of leadership research still commits the fundamental flaws of over-attribution, decontextualisation and valorisation by their conceptual and methodological construction of the object of leadership). There are also established bodies of work that seek to broaden and reconceptualise leadership beyond formal positions or bodies of leaders (e.g. distributed leadership, postheroic leadership, leadership as practice etc). Nevertheless, these bodies of work suffer from being colonized and appropriated for functionalist or instrumentalist purposes or perspectives because they still valorise leadership, and tend to focus on leadership alone rather than in conjunction with power and other social asymmetries.

We need not only pluralist perspectives on leadership, but also pluralist perspectives on broader issues of social ordering (for instance, organization, co-ordination, conflict, power, authority, management, administration, domination, resistance ...). These topics tend to be studied singly, but while a disciplinary focus is understandable, interdisciplinary and transdisciplinary approaches are needed. This also has ramifications for writing and publishing leadership research. Even though the articles in this Special Issue have focused on only two phenomena from the initially desired three (leadership and crisis, but not authority), the scholarly community needs to be able to write, accept and read more complex writing forms, with multiple themes and perspectives. We argue, that it is only through such complex forms is it possible to satisfactorily acknowledge, account for, and include in the analyses, broader political ecologies and political economies, which while potentially insufficient are an essential starting point for any satisfactory account of leadership, authority or crisis.

\section{References}

Bligh MC, Kohles JC and Pillai R. (2005) Crisis and Charisma in the California Recall Election. Leadership 1: 323-352.

Boin A and 't Hart P. (2003) Public leadership in times of crisis: Mission impossible? Public Adm. Rev. 63: 544-553.

Boin A, 't Hart P and McConnell A. (2009) Crisis exploitation: political and policy impacts of framing contests. Journal of European Public Policy 16: 81-106.

Chambers L, Drysdale J and Hughes J. (2010) The future of leadership: A practitioner view. European Management Journal 28: 260-268.

Contractor NS, DeChurch LA, Carson J, et al. (2012) The topology of collective leadership. The Leadership Quarterly 23: 994-1011.

FaIrclough N. (2010) Critical Discourse Analysis: the critical study of language, Harlow: Longman.

Foley M. (2013) Barack Obama and the Calculus of Presidential Ambiguity. Political Studies Review 11: 345-357.

Grint K. (2005) Problems, problems, problems: The social construction of 'leadership'. Human Relations 58: 1467-1494.

Grint K. (2010) The cuckoo clock syndrome: addicted to command, allergic to leadership. European Management Journal 28: 306-313.

Gruber J. (2010) Key principles of community-based natural resource management: a synthesis and interpretation of identified effective approaches for managing the commons. Environmental Management 45: 52-66. 
Habermas J. (1975) Legitimation crisis, Boston: Beacon Press.

Knights D and McCabe D. (2015) 'Masters of the Universe': Demystifying Leadership in the Context of the 2008 Global Financial Crisis. British Journal of Management 26: 197210.

Letsch C. (2014) A year after the protests, Gezi Park nurtures the seeds of a new Turkey. The Guardian. London: Guardian Media Group.

Letsch C. (2015) Gezi Park protest trial: Turkish court acquits all 26 defendants. The Guardian. London: Guardian Media Group.

Mabey C and Morrell K. (2011) Leadership in crisis: 'Events, my dear boy, events'. Leadership 7: 105-117.

Madera JM and Smith DB. (2009) The effects of leader negative emotions on evaluations of leadership in a crisis situation: The role of anger and sadness. The Leadership Quarterly 20: 103-114.

Meindl JR, Ehrlich SB and Dukerich JM. (1985) The romance of leadership. Administrative Science Quarterly 30: 78-102.

Mertkan S. (2014) In search of leadership: what happened to management? Educational Management Administration \& Leadership 42: 226-242.

Musselwhite C and Jones R. (2004) Dangerous opportunity: making change work, Bloomington, IN: Xlibris Corporation.

Obolensky N. (2014) Complex Adaptive Leadership: embracing paradox and uncertainty, Farnham: Gower.

Perry F. (2015) Two years after Istanbul's protests, will Gezi Park be redeveloped after all? The Guardian. London: Guardian Media Group.

Probert J and Turnbull James K. (2011) Leadership development: Crisis, opportunities and the leadership concept. Leadership 7: 137-150.

Sayer A. (2000) Realism and Social Science, London: Sage.

Ulmer RR, Sellnow TL and Seeger MW. (2014) Effective Crisis Communication: moving from crisis to opportunity, Thousand Oaks, CA: Sage.

Virilio P. (2012) The administration of fear, Los Angeles: Semiotext(e).

Weick KE. (1988) Enacted sensemaking in crisis situations. Journal of Management Studies 25: 305-317.

Williams EA, Pillai R, Lowe KB, et al. (2009) Crisis, charisma, values, and voting behavior in the 2004 presidential election. The Leadership Quarterly 20: 70-86. 